\title{
RARE CAUSES OF SPONTANEOUS PNEUMOTHORAX: TWO CASE REPORTS
}

\author{
V. Hadzhiminev* \\ Department of Special Surgery, Medical University - Plovdiv, Plovdiv, Bulgaria
}

\begin{abstract}
Secondary spontaneous pneumothorax (SSP) may be a result of different rare diseases. In the following article are presented two interesting cases of SSP related to genetic disorders - Ehlers-Danlos syndrome (EDS) and Neurofibromatosis type 1 (NF-1). We share our clinical, laboratory and imaging findings as well as the surgical techniques we used and the postoperative complications we had. We performed a detailed literature review on this topic.
\end{abstract}

Key words: spontaneous pneumothorax, Ehlers-Danlos syndrome, neurofibromatosis type 1, von Recklinghausen's disease

\section{INTRODUCTION}

Leading causes for secondary spontaneous pneumothorax (SSP) worldwide are the chronic obstructive pulmonary disease (COPD) and the pulmonary emphysema.[1] In rare cases, SSP may be a result of different genetic disorders such as Ehlers-Danlos syndrome (EDS) and Neurofibromatosis type 1 (NF-1).

Ehlers-Danlos syndrome is a rare genetic disorder that affects connective tissue. It is manifested with musculoskeletal features (hypermobility of the joints, kyphoscoliosis, pes planus), skin abnormalities (hyperextensibility, scaring, molluscoid pseudotumors) and cardiovascular features (valvular prolapse, aortic dilation, weakness of blood vessels). EDS is classified into 6 types according to the clinical and genetic differences; classic, hypermobility, vascular, kyphoscoliotic, arthrochalasia, and dermatosparaxis. One of the features of that disease is pneumothorax. It is observed more frequently in EDS type IV (vascular). [2, 3]

Neurofibromatosis-1 also known as von Recklinghausen's disease is another genetic

*Correspondence to: Velizar Hadzhiminev, Department of Special Surgery, Medical University - Plovdiv: Bulgaria, Plovdiv, 15 Vassil Aprilov Blvd. email: velizar.hadzhiminev@mu-plovdiv.bg, phone number: +359883339189 disorder that is autosomal dominant. It is aclinical diagnosis with the pathognomonic skin findings usually manifesting in the first decade. Genetic testing is not routinely performed for the diagnosis of that disease. Clinically, NF-1 is presented with neurofibromas, axillary freckling, "café-aulait" macules, iris hamartomas and [4, 5]. Lung manifestations that usually include interstitial lung disease (ILD), thin walled bullae and eventually pneumothorax are other features of the disease. They are reported in up to $20 \%$ of adult patients with NF-1. [6]

The aim of this article is to report two cases of secondary spontaneous pneumothorax that are result of rare pathologies - EDS and NF-1 and to present our diagnostic and therapeutic approach.

\section{CASE PRESENTATION \# 1}

A 16-year-old male patient was admitted to the Department of Special surgery of University Hospital "Sveti Georgi" with complaints of sudden right chest pain and shortness of breath for 3 hours. Physical examination revealed no fever, asthenic habitus, translucent skin with visible underlying vessels, joint hypermobility, and kyphoscoliosis, missing breathing sounds in the right, respiratory rate $25 / \mathrm{min}$, normal heart rate and blood pressure. Relevant laboratory findings at the time of admission 
were following: HGB - $154 \mathrm{~g} / \mathrm{l}$; RBC - 5.03; WBC - 10.21; PLT - 269; glucose $5.6 \mathrm{mmol} / 1$; t. protein $-81 \mathrm{~g} / \mathrm{l} ; \mathrm{PT}-77.4 \%$. A chest X-ray revealed a right pneumothorax. A right-sided thoracocentesis with placing a drain tube was performed. A persistent air-leak was observed for 5 days (> $200 \mathrm{ml} / \mathrm{min}$ on Thopaz - Medela pump). Chest CT was performed and revealed partial right pneumothorax, subcutaneous emphysema and bullous changes of both lungs.

(Figure 1) On the next day the patient was operated and VATS with right apical resection was performed. The postoperative period was uneventful. After consultation with paediatrician the patient was transferred to the

\section{HADZHIMINEV $V$.}

Paediatric department for diagnosis and treatment - different types of connective tissue disorders and genetic disorders were discussed as possible comorbidities. The further examination showed mitral valve prolapse, aortic root dilation, molluscoid pseudotumors, hyperpigmentation of the operative scar. The following and the previous clinical findings were strongly suspicious for Ehlers-Danlos syndrome and genetic testing was performed. The results showed mutation of type 1 collagen COL3A1 which proven the diagnosis EDS type IV. The six-month follow-up of the patient registered no recurrences of the pneumothorax.

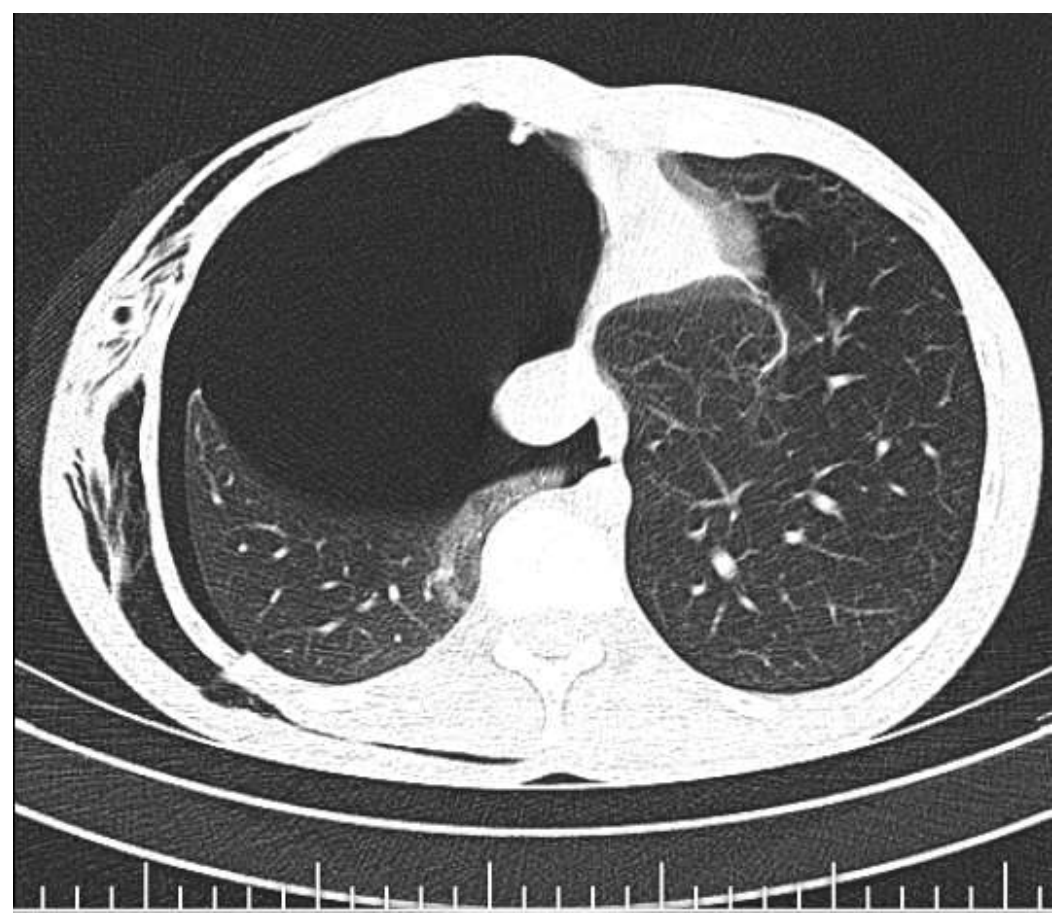

Figure 1. Chest computed-tomography Clinical case \#1: Right pneumothorax and a subcutaneous emphysema

\section{CASE PRESENTATION \# 2}

A 68-year-old female, non-smoker, with a 50year history of neurofibromatosis type 1 presented with dyspnea and right chest pain was admitted to our department. She informed about previous thoracocentesis a year ago due to right pneumothorax. Physical examination revealed no fever, short stature, several caféau-lait spots, two axillary freckles, multiple neurofibromas (more than 10) all over the body, weakened breathing sounds in the right, respiratory rate $24 / \mathrm{min}$, blood pressure $150 / 90$ $\mathrm{mm} \mathrm{Hg}$, pulse rate $-120 / \mathrm{min}$. Relevant laboratory findings at the time of admission were following: HGB - $147 \mathrm{~g} / \mathrm{l}$; RBC - 5.03; WBC - 7.36; PLT - 261; glucose $4.8 \mathrm{mmol} / \mathrm{l}$; t. protein $-82 \mathrm{~g} / \mathrm{l} ; \mathrm{PT}-89.7 \%$. A chest X-ray revealed a right pneumothorax. A right-sided thoracocentesis with placing a drain tube was performed. Chest CT was performed and revealed partial right pneumothorax, several large bullae of the inferior lobe of the right lung, diffuse bullous changes of both lungs. (Figure 2) The patient had a recurrent ipsilateral pneumothorax and she was indicated for surgery. Right thoracotomy with inferior lobectomy was performed. (Figure 3) The postoperative period was uneventful. The patient was discharged on the eleventh day. A control X-ray was performed six months after the surgery which revealed a higher position of the right diaphragm and slight pleurofibrosis. 


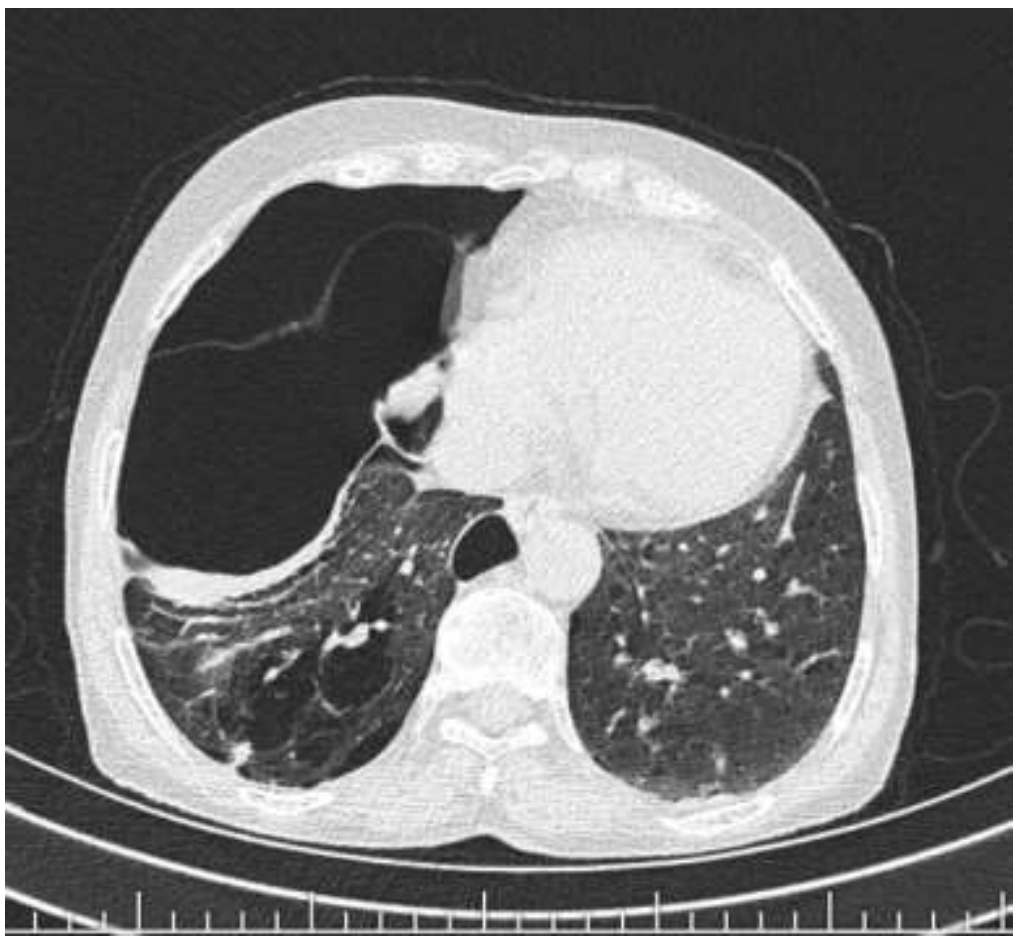

Figure 2. Chest computed-tomography Clinical case \#2: Large bullae and bilateral bullous changes

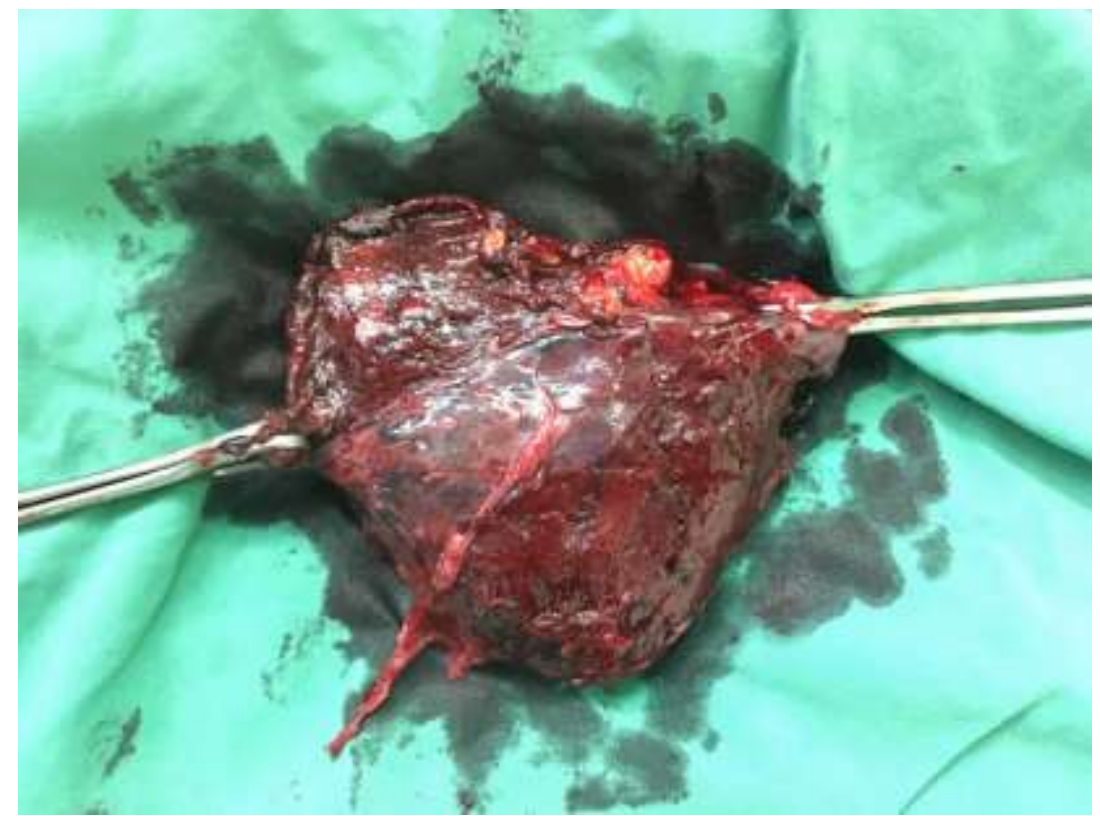

Figure 3. Gross pathology Clinical case \#3: Right inferior lobe with a large bulla

\section{DISCUSSION}

In more than $60 \%$ of the cases SSP is caused by COPD and pulmonary emphysema. However, it could be observed in patients with rare diseases such as EDS and NF-1. [7]

In 1967 Barabas et al. first described EDS type IV (vascular).[8] This form is rare and affects approximately $4 \%$ of all EDS cases. These patients are at great risk of early death at young age due to aortic dissection, arterial rupture, or bowel perforation. If compared with the other subtypes of EDS, the patients with EDS type IV have fragile, but inextensible connective tissues. [9] Ayres et al. researched the abnormalities of the lungs and thoracic cage in patients with EDS. They found that although not usually related to issues of mortality, pulmonary complications including pneumothorax, hemothorax, and intrapulmonary hematoma have been documented, predominantly in young adults 
diagnosed with EDS.[10] The pleural tissue in these patients is very fragile which may cause the formation of blebs or/and bullae followed by rupture and pneumothorax. The incidence of spontaneous pneumothorax in EDS type IV is higher than in other subtypes accounting approximately $16 \%$ of the cases. [2] In our case genetic testing of the patient revealed that he had EDS type IV. Several authors reported for patients with EDS related pneumothorax. Park et al. performed video-assisted bullae resection as a method of choice. We used the same procedure in our case after the initial thoracocentesis and the persistent air-leak that followed. Purohit et al. and Ishiguro et al. used thoracotomy-resection in their patients after unsuccessful VATS-interventions. Persistent air-leak was the most common complication reported by us and the other authors. [11-14]

NF-1 is a genetic disorder that affects the neuroectodermal and esodermal tissues. [15] Lung involvement in those patients is not infrequent and it is manifested with ILD and/or bullae. In 1963 Davies first reported the association between NF-1 and ILD. [16] Several other authors also described coexisting lung diseases in 10-20\% of patients with NF-1. $[6,16]$ In their retrospective case series Zamora et al. reviewed 64 patients with NF-1. They found out that $25 \%$ of them had emphysema and cysts and 50\% showed reticular abnormalities and bullae. Bullous changes usually engaged the upper and lower lobes. Rupture of a bulla results a pneumothorax. It usually presents in the fourth or fifth decade, earlier in tobacco users. [17] Different authors reported for cases of NF-1 related pneumothoraces. [18, 19] SSP in these patients could be challenging for the thoracic surgeon because of the common recurrences and postoperative complications. Kim et al. used VATS-lobectomy as a method of choice and had persistent air-leak as a complication which they managed with polyglycolic acid felt. [20] In our case, we had a female patient with NF-1 and recurrent right pneumothorax that occurred after the fourth decade of life as reported by other authors. We didn't perform genetic testing because of the pathognomonic features of the disease that she had. Unlike the other authors who preferred VATSintervention we used right thoracotomy with lobectomy as a surgical method of choice and had no postoperative complications.

\section{CONCLUSION}

\section{HADZHIMINEV V.}

In this study, we presented two cases of secondary spontaneous pneumothorax related to rare pathologies. We shared our clinical and surgical approach. To finish with, the occurrence of spontaneous pneumothorax in patients with EDS and NF-1 requires special consideration because of the life-threatening symptoms, the high recurrence rate, and postoperative complications, even if surgery is performed.

\section{ABBREVIATIONS}

SSP - secondary spontaneous pneumothorax COPD - Chronic obstructive pulmonary disease EDS - Ehlers-Danlos syndrome NF-1 - Neurofibromatosis type 1 ILD - interstitial lung disease

\section{References}

1. Fettal N, Taleb A. Pneumothorax secondary to chronic obstructive pulmonary disease. Eur Respir J. 2012; 40(56): P558.

2. Beighton P, De Paepe A, Steinmann B, et al. Ehlers-Danlos syndromes: revised nosology, Villefranche, 1997. EhlersDanlos National Foundation (USA) and Ehlers-Danlos Support Group (UK). Am J Med Genet 1998;77:31-7.

3. Dar RA, Wani SH, Mushtaque M, et al. Spontaneous hemopneumothorax in a patient with Ehlers-Danlos syndrome. Gen Thorac Cardiovasc Surg 2012; 60:587-9.

4. Zamora AC, Collard HR, Wolters PJ, Webb WR, King TE. Neurofibromatosis associated lung disease: a case series and literature review. Eur Respir J 2007; 29: 210-14.

5. Rossi SE, Erasmus JJ, Page McAdams H, Donelly LF. Thoracic manifestations of neurofibromatosis-I. Am $J$ Roentgenol 1999; 173: 1631-8.

6. Oikonomou A, Vadikolias $\mathrm{K}$, Birbilis $\mathrm{T}$, Bouros D, Prassopoulos P. HRCT findings in the lungs of non-smokers with neurofibromatosis. Eur J Radiol 2011; 80: 520-23.

7. Van Schil PE, Hendriks JM, De Maeseneer MG, Lauwers PR. Current management of spontaneous pneumothorax. Monaldi Arch Chest Dis. 2005;63(4):204-12. doi: 10.4081/monaldi.2005.622.

8. Barabas AP. Heterogeneity of the EhlersDanlos syndrome: description of three clinical types and a hypothesis to explain 
the basic $\operatorname{defect}(\mathrm{s}) . \operatorname{Br} M e d J$ 2: 612-613, 1967.

9. Oderich GS, Panneton JM, Bower TC, et al. The spectrum, management and clinical outcome of Ehlers-Danlos syndrome type IV: a 30-year experience. J Vasc Surg 42: 98-106, 2005.

10.Ayres JONG, Pope FM, Reidy JF, Clark TJH. Abnormalities of the lungs and thoracic cage in the Ehlers-Danlos syndrome. 1985;(December 1984):300-305.

11.Nakagawa H, Wada H, Hajiro T, Nagao T, Ogawa E. Ehlers -Danlo s Syndrome T ype IV with Bil ateral Pneumothorax. 2015:3181-3184.doi:10.2169

12.Park MA, Shin SY, Kim YJ, Park MJ, Lee H. Vascular Ehlers - Danlos syndrome with cryptorchidism, recurrent pneumothorax, and pulmonary capillary hemangiomatosislike foci. 2017;0(July).

13.Purohit N, Marsland D, Roberts N, Townsend E. Case report - Pulmonary Haemo-pneumothorax and haemoptysis in a patient with suspected Ehlers - Danlos syndrome. 2009;9:130-131. doi:10.1510/icvts.2009.204313

14.Ishiguro $\mathrm{T}$, Takayanagi N, Kawabata $\mathrm{Y}$, Matsushima H, Report C. Ehlers-Danlos Syndrome with Recurrent Spontaneous Pneumothoraces and Cavitary Lesion on

\section{HADZHIMINEV $V$.}

Chest X-ray. 2009:717-722.

doi:10.2169/internalmedicine.48.1818

15. Arun D, Gutmann DH. Recent advances in neurofibromatosis type 1. Curr Opin Neurol 2004; 17: 101-5.

16.Davies PDB. Diffuse pulmonary involvement in Von Recklinghausen's disease: a new syndrome. Thorax 1963; 18: 198.

17.Nardecchia E, Perfetti L, Castiglioni M, Natale D Di, Imperatori A, Rotolo N. Bullous lung disease and neurofibromatosis type-1. 2012:105-107.

18. Ayed Della S, Kotti A, Ben Sik Ali H, Ayed S, Fekih Hassen M, Elatrous S. Pneumothorax spontané et maladie de Recklinghausen : à propos d'un cas [Spontaneous pneumothorax and Recklinghausen's disease: a case report]. Rev Pneumol Clin. 2012;68(3):202-204. doi:10.1016/j.pneumo.2011.08.001

19.Engdahl R, Vivas D, Lajam F. Spontaneous pneumothorax as initial presentation of neurofibromatosis. Am Surg. 2010;76(9):1034.

20.Kim S, Kim D. Management of long-term persistent air leakage developed after bullectomy for giant bullous lung disease associated with neurofibromatosis type 1 . 2016;8(1):140-143.

doi:10.3978/j.issn.2072-1439.2016.01.21 